Article

\title{
Building a Wind Power Plant from Scrap and Raising Public Awareness for Renewable Energy Technology in a Circular Economy
}

\author{
Fabian Schoden *, Alina Siebert, Alparslan Keskin, Konstantin Herzig, mAjkel Straus and \\ Eva Schwenzfeier-Hellkamp \\ Institute for Technical Energy Systems (ITES), Bielefeld University of Applied Sciences, 33619 Bielefeld, \\ Germany; alina.siebert@fh-bielefeld.de (A.S.); alparslan.keskin@fh-bielefeld.de (A.K.); \\ konstantin.herzig@fh-bielefeld.de (K.H.); mAjkel.straus@fh-bielefeld.de (M.S.); \\ eva.schwenzfeier-hellkamp@fh-bielefeld.de (E.S.-H.) \\ * Correspondence: fabian.schoden@fh-bielefeld.de; Tel.: +49-521-106-7386
}

Received: 20 November 2019; Accepted: 18 December 2019; Published: 21 December 2019

\begin{abstract}
Putting renewable energy to good use is necessary to deal with one of the greatest challenges of our time, namely, climate change. One problem, however, is that the technology we are using today turns into toxic waste at the end of its useful life, which in particular concerns the blades of wind turbines. We investigated how the ideas of a circular economy can be applied to address this issue. To this end, we built a small wind turbine almost entirely from used mAterials. The social purpose of this is to raise public awareness about renewable energy technology that is part of a circular economy. Therefore, we chose a reliable and easy-to-build concept for a small wind turbine, which can be reproduced in a "Do It Yourself" (DIY) approach. The core challenges we had to face consisted of how to acquire appropriate used mAterials and how to improve the efficiency of the system to obtain adequate electrical power. With a financial investment of less than $€ 100$, we built a Savonius wind turbine for use in, for example, a private garden to charge a power bank or other USB-chargeable devices.
\end{abstract}

Keywords: circular economy; renewable energy; wind turbine; sustainability; energy supply; harness the wind; Savonius wind turbine

\section{Introduction}

The expansion of wind energy use is an essential part of reaching the goals of the Paris Agreement [1]. Especially in Germany, wind energy is widely available [2]. However, due to stricter approval procedures, the number of newly built on-shore wind power plants in 2018 was drastically reduced and this trend continues in 2019 [3]. To sensitize the public to renewable energies, a Savonius wind turbine was built in this study. This Savonius wind turbine cannot replace large-scale wind turbines, since the electric power output is limited to $1.5 \mathrm{~W}$.

Another problem with large-scale wind turbines is that in the search for a lower price per kilowatt hour and, hence, greater efficiency, the size of wind turbines has increased and, thus, the requirements for the mAterials used have risen as well. At some point, the mAterial, for instance, aluminum or polyvinyl chloride (PVC), of rotor blades had to be replaced by glass and carbon fiber composites, which provide excellent stiffness while being lightweight at the same time. However, recycling these mAterials results in low-value mAterials [4]. Of all recycling processes, pyrolysis is currently the only one used on a commercial scale [5]. That is why wind power plants pose an enormous waste problem in the future. It is estimated that, by 2028 , the waste from rotor blades will amount to 330,000 $\mathrm{t} /$ year, which is bound to increase to $418,000 \mathrm{t} /$ year by 2040 [6]. 
In addition, in an accident, the blades of a turning wind turbine mAy be torn to pieces. The area around the power plant is then polluted with slivers of fiberglass, which pose, when ingested, a threat to animals and humans [7]. To stop the end of pipe solutions, renewable mAterial such as wood or metal should be used to build wind power plants instead of composites [8]. A considerable part of the volume of rotor blades consists of balsa wood, which could be recycled but it is a complex process to separate it from other composite parts [9]. It is important to design new renewable energy harvesting technologies which are easy to mAintain and completely recyclable.

Materials used in wind turbines, such as steel, aluminum, and copper, are already recycled to a high percentage; experts from Vestas suggest over $90 \%$. However, blades and concrete are landfilled [10]. Researchers are working on potential solutions for recycling the blades of wind turbines as well. There are approaches for shredding rotor blades and using them as filler in concrete [11]. Rahimizadeh et al. experimented with glass fiber composites from wind turbine waste and enhanced the structural stiffness of 3D-printed fused filament fabrications [12]. Furthermore, several parties are working on standards for the sustainable dismantling of wind turbines, for instance, RDRWind e.V. and the Federal Environment Agency of Germany $[13,14]$.

These approaches look into end-of-life solutions, which are necessary when taking into account the huge amount of waste from rotor blades [6]. However, in a circular economy, the aim is to eliminate waste by design. That is why, in addition to end-of-life recycling solutions, there is a need for circular design approaches for wind turbines.

In this study, we built a Savonius wind turbine from waste mAterial. The goal was to demonstrate that a Savonius wind turbine can be mAde from used mAterial in a "Do It Yourself" (DIY) approach to raise public awareness for renewable energy technology in a circular economy. This type of wind turbine is easy to mAintain, and its components can be reused and recycled after its useful life [15]. Therefore, it is an example of renewable energy generation for the circular economy. The circular economy is a new economic model in which companies and societies pursue the goal of eliminating the concept of waste by design [16]. This concept not only counters the resource shortage but also is important in tackling climate change with holistic concepts as well as new business models and products [17].

Related works on small wind turbines have focused on the use of wind turbines in rural areas [18]. Santhakumar et al. build a Savonius wind turbine, which can be placed close to highways and supply rural areas with electricity [19]. Devecitech, a young start-up, is already monetizing this idea. With their ENLIL wind turbine, it is possible to use the wind produced by vehicles on highways to generate electricity [20]. Rodrigues et al. focused on developing a guideline for building wind turbines in rural areas and also used scrap mAterials [21].

In this work, we focused on building a wind turbine in, for example, city gardens to sensitize the public to renewable energies. Furthermore, we want to connect the idea of DIY renewable energy technology, mAde from renewable or recyclable mAterial, with the economic model of the circular economy. To generate power for a circular economy, the use of renewable energies is essential. These technologies need to be part of the circular economy and not cause waste problems after their useful life [6].

To sensitize the public to renewable energy, we used very common mAterials and tools to enable a DIY approach. Parents and their children can build such a plant in their garden and mAke positive experiences with renewable energies. On the one hand, the amount of wind energy that can be harvested by such a wind power plant is limited and not comparable to commercial wind turbines. On the other hand, people can experience how long it takes the wind to charge their phone. In this study, we used a hub dynamo, which is limited to an electric power output of $3 \mathrm{~W}$. Nevertheless, it is possible to charge a smartphone or a power bank with this system. The work of William Kamkwamba, who educated himself about wind energy and built a wind power plant from scavenged mAterials, inspired this project [22]. Since we used a DIY approach, this project could also be an option to enable 
people in isolated areas or areas where no electrical grid is available to harness the wind to generate electrical or mechanical energy.

\section{Materials and Methods}

In this work, we decided to build a Savonius wind turbine because it is a robust and reliable system [15]. Furthermore, we were able to acquire the right mAterials for this type of wind turbine (Figure 1).

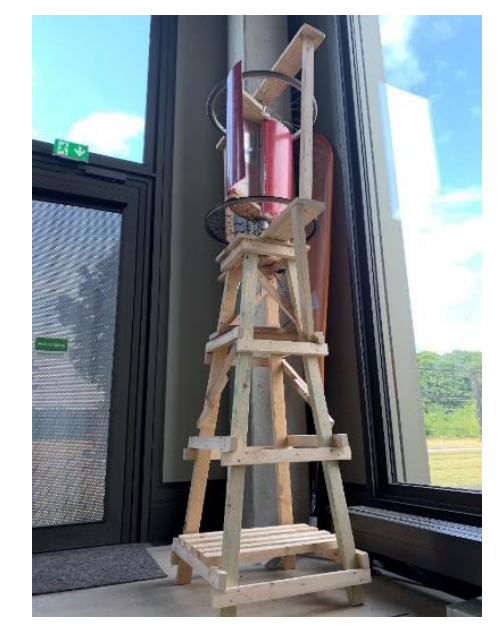

Figure 1. Final design of the Savonius wind turbine together with the tower.

Since we used a DIY approach and built such a wind turbine in private gardens, security for kids playing around the wind turbine was also an important criterion. The tower is robust and lifts the rotor $140 \mathrm{~cm}$ up. In this way, the risk of children being hurt is reduced. Another benefit of the higher position is that the rotor is lifted above some obstacles such as garden fences, which otherwise would reduce the wind speed and, thus, the electric energy harvested. Since we wanted children and laypersons to rebuild this or a similar wind turbine, we rated safety, reliability, and easy installation higher than efficiency. After planning the construction, we had to gather the materials.

The type of wind turbine which can be built using a DIY approach depends on the individual field of application and the scrap mAterials that are available. This is why the size, appearance, and electrical components can vary from project to project. While using scrap mAterials, a high level of creativity is required to transform the available mAterials into the planned wind turbine.

In our case, we could obtain a number of old pallets and metal parts from a university junkyard. We had to buy some fixing mAterial, a charge controller [23], and an old bicycle rim with a hub dynamo [24]. A complete list of all mAterials, place of procurement, and the price can be found in Table 1.

Table 1. List of mAterials used, their place of procurement, and the price.

\begin{tabular}{ccc}
\hline Material & Place of Procurement/Purchase & Price \\
\hline 26 in. bicycle rim with hub dynamo [24] & Private sale & $€ 25$ \\
26 in. bicycle rim & Workshop of university & $€ 0$ \\
Wooden parts & Junkyard of university & $€ 0$ \\
Metal sheets & Junkyard of university & $€ 0$ \\
Charge controller [23] & Voelkner (shop for electronics) & $€ 23.99+€ 5.95$ shipping cost \\
200 screws & Hardware store & $€ 5.70$ \\
Four nuts (M10) & Hardware store & $€ 0.47$ \\
Four shims (M10) & Hardware store & $€ 2.93$ \\
Threaded rod with diameter of 10 mm and length of $100 \mathrm{~cm}$ & Hardware store & $€ 1.40$ \\
\hline & Sum: & $€ 65.44$ \\
\hline
\end{tabular}

We were able to use metal and wooden waste from the university, as depicted in Figures 2 and 3. 


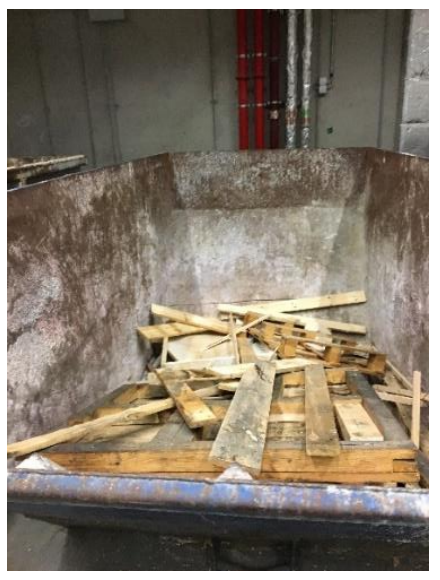

(a)

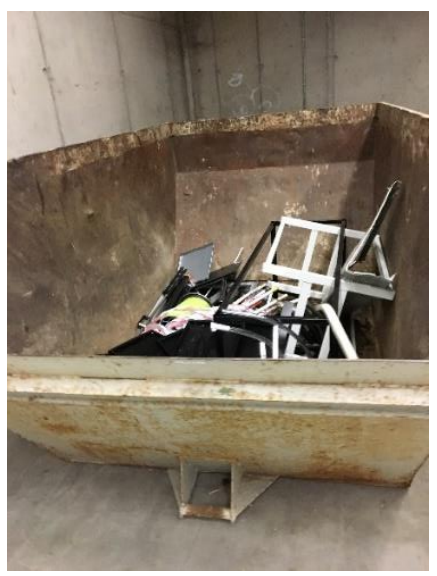

(b)

Figure 2. The junkyard of the university: (a) wooden and (b) metal parts.

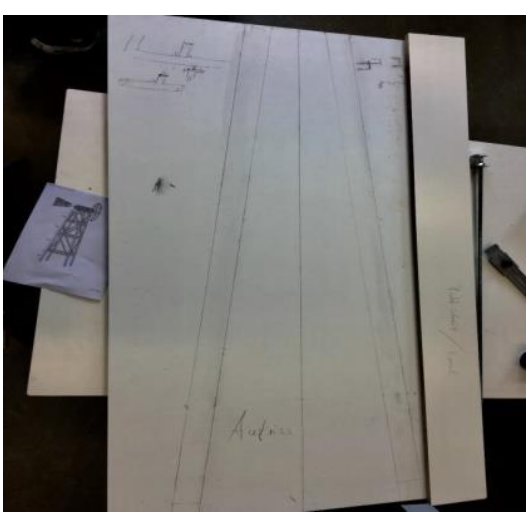

(a)

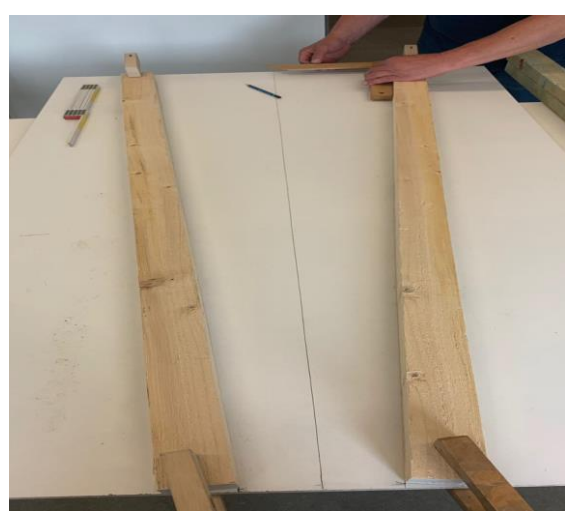

(b)

Figure 3. Construction process of the lattice tower I: (a) vertical plan; (b) fixing the first two legs of the lattice tower.

\subsection{Constructing the Tower}

We decided to build a lattice tower because it is a simple and robust design. The wood and metal we used was gathered from the university's junkyard (Figure 2). We found some old pallets and some metal sheets. We took the pallets apart with a hammer and a crowbar to obtain battens. The tower had four levels and consisted of 35 wooden parts in total.

The following list displays the dimensions of the levels of the tower:

1. Top level (support platform for the rotor):

1. Four battens: length $32 \mathrm{~cm}$, width $5 \mathrm{~cm}$, and depth $3 \mathrm{~cm}$

2. Two battens: length $36.5 \mathrm{~cm}$, width $14 \mathrm{~cm}$, and depth $2 \mathrm{~cm}$

2. Third level (support platform for electrical devices):

1. Four battens: length $43 \mathrm{~cm}$, width $5 \mathrm{~cm}$, and depth $3 \mathrm{~cm}$

2. Two battens: length $42 \mathrm{~cm}$, width $13 \mathrm{~cm}$, and depth $2 \mathrm{~cm}$

3. Second level (stabilization):

1. Four battens: length $56 \mathrm{~cm}$, width $5 \mathrm{~cm}$, and depth $3 \mathrm{~cm}$

4. First level (platform for additional weight to lower the center of gravity of the construction):

1. Four battens: length $63 \mathrm{~cm}$, width $5 \mathrm{~cm}$, and depth $3 \mathrm{~cm}$ 
2. Five battens: length $62 \mathrm{~cm}$, width $5 \mathrm{~cm}$, and depth $3 \mathrm{~cm}$

The four legs of the tower were $150 \mathrm{~cm}$ long, $6 \mathrm{~cm}$ wide, and $4 \mathrm{~cm}$ deep.

To further strengthen the construction, six diagonal battens were mounted, as can be seen in Figure 1.

- Two battens (between the top and the third level): length $40 \mathrm{~cm}$, width $2 \mathrm{~cm}$, and depth $3.3 \mathrm{~cm}$

- $\quad$ Four battens (between the third and the second level): length $32 \mathrm{~cm}$, width $2 \mathrm{~cm}$, and depth $3.3 \mathrm{~cm}$. In this case, two battens were mounted together, as can be seen in Figure 1.

To connect all mAterials, a vertical plan was drafted, as can be seen in Figure 3a. Two legs were fixed on the vertical plan, as can be seen in Figure $3 b$.

The angle between the legs and the first platform was $96^{\circ}$. The cross struts for each of the four levels were then cut to the appropriate length with a wood saw.

The dimensions of the tower depicted in Figure 4 were

- Height $140 \mathrm{~cm}$

- Width $70 \mathrm{~cm}$

- Depth $70 \mathrm{~cm}$.

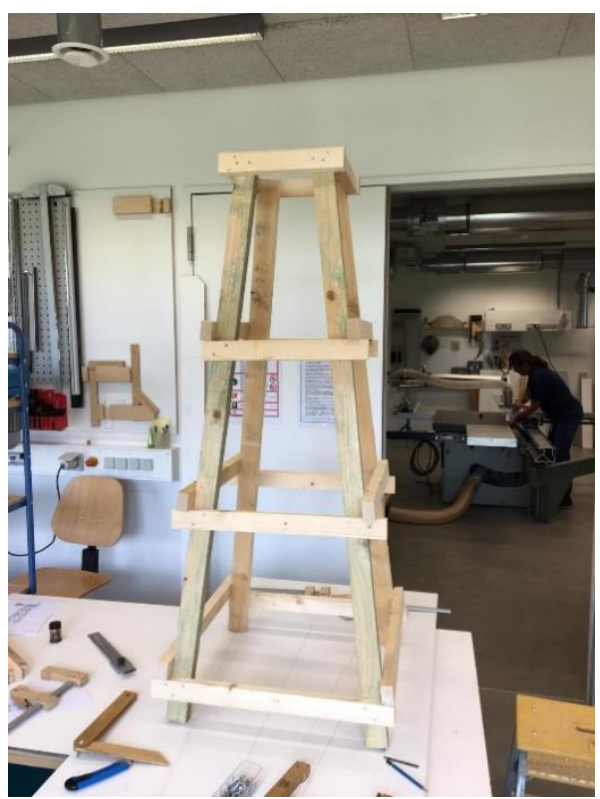

(a)

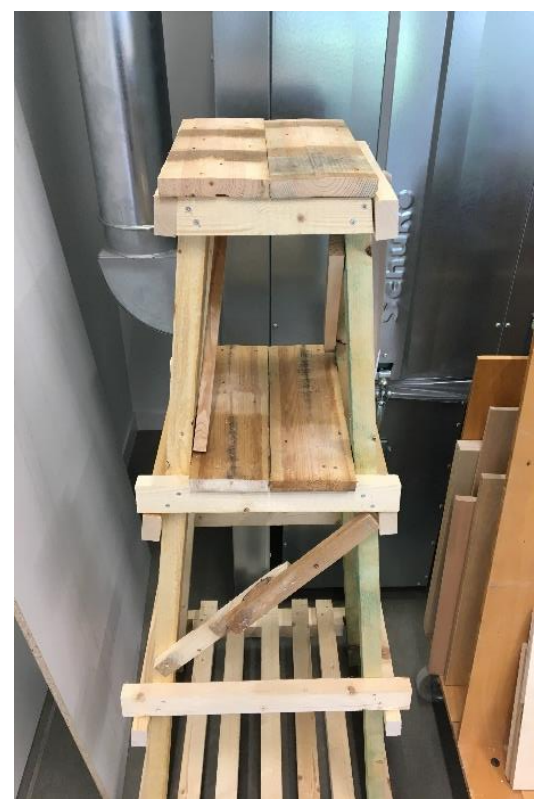

(b)

Figure 4. Construction process of the lattice tower II: (a) constructing the levels of the tower; (b) finished lattice tower.

Due to its width and the possibility of putting weight on the lowest platform to lower the center of gravity, the statics of the tower is sufficient to protect it from common gusts of wind because the wind has no point of attack. To mAke the wooden wind turbine weatherproof, some finish or wax should be applied on the tower's surface. One possible solution could be plant oil or beeswax [25].

\subsection{Constructing the Rotor}

The rotor was mAde from two metal pieces, which were probably old metal shelves. The metal sheets were cut to $70 \mathrm{~cm}$ length, $40 \mathrm{~cm}$ width, and $2 \mathrm{~mm}$ depth. They were deburred to reduce the risk of injury. It would also be possible to use lighter mAterials such as plastic or wood. 
To connect the two metal sheets, we mAde two S-shaped wooden elements with a length of $68 \mathrm{~cm}$, as can be seen in Figure 5a. In the middle of the S-shaped batten, we drilled a hole so as to connect the bicycle rims with the rest of the construction. We mounted the metal sheets with screws on it. The result can be seen in Figure $5 b$.

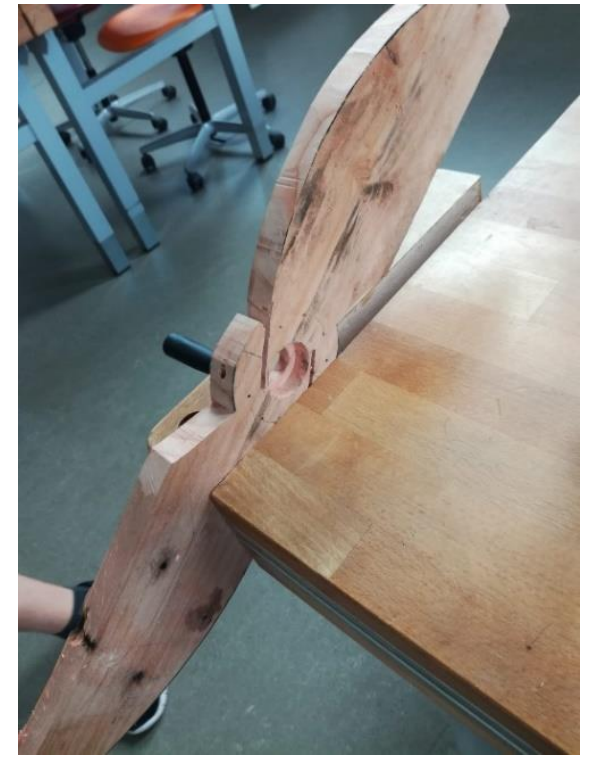

(a)

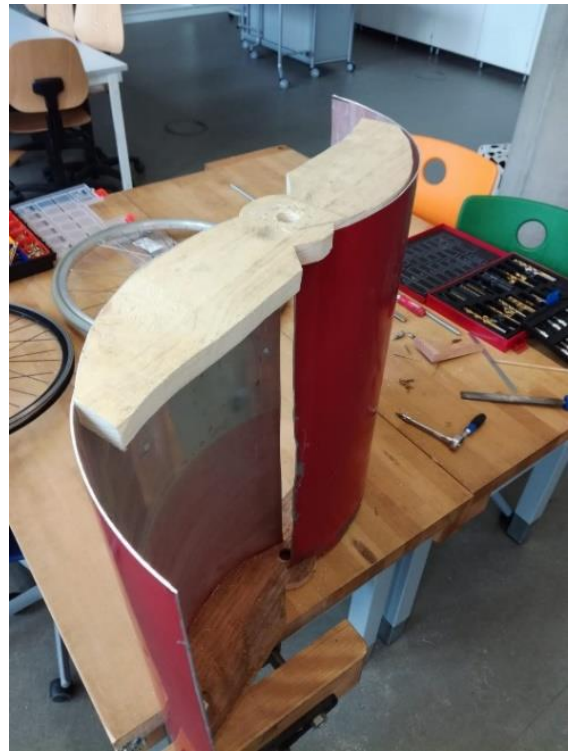

(b)

Figure 5. Construction process of the rotor I: (a) constructing the S-shaped wooden element;

(b) mounting the metal sheets and the S-shaped element together.

Furthermore, we used a 26 in. bicycle rim with a hub dynamo for transforming wind energy to electrical energy. Another old bicycle rim was found in the workshop of the university and was used as a counterpart. To connect the bicycle rims with the rotor and the tower, we used a threaded rod. The threaded rod was also the axis of the rotor, as visible in Figure 6.

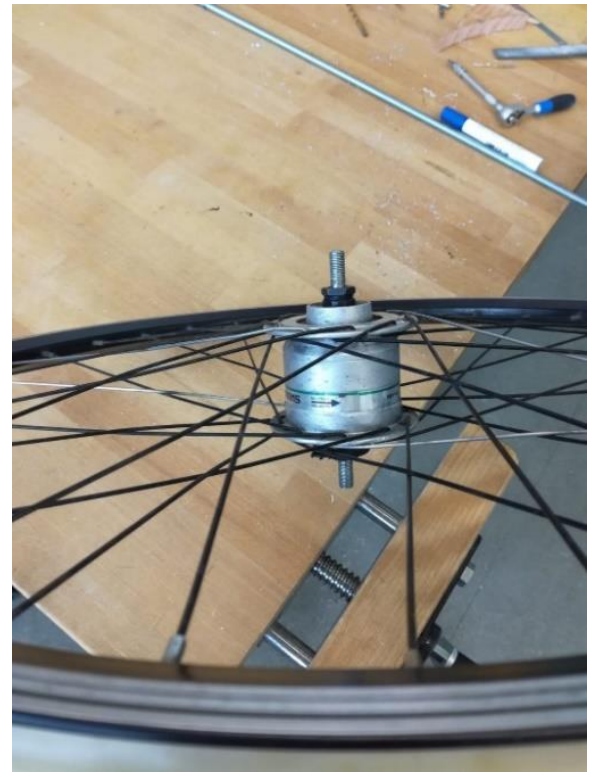

(a)

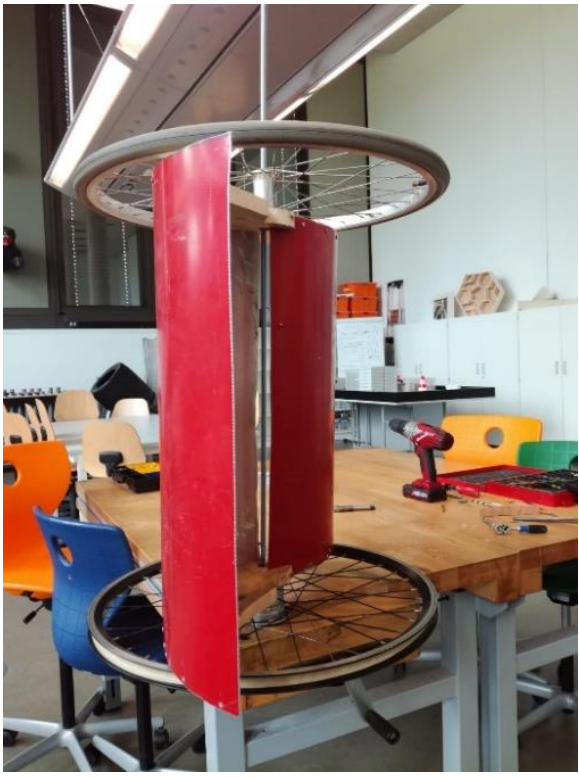

(b)

Figure 6. Construction process of the rotor II: (a) axis of the bicycle rim with a hub dynamo; (b) mounting the threaded rod and finishing the rotor. 
We fixed the threaded rod with two nuts and shims for each bicycle rim. Furthermore, we built a wooden frame to support the structure, as can be seen in Figure 1.

The dimensions of the wooden frame were

- $\quad$ Two battens: length $100 \mathrm{~cm}$, width $13 \mathrm{~cm}$, and depth $2.3 \mathrm{~cm}$

- Two battens: length $83 \mathrm{~cm}$, width $4.5 \mathrm{~cm}$, and depth $3.3 \mathrm{~cm}$

- $\quad$ Two battens: length $59 \mathrm{~cm}$, width $5 \mathrm{~cm}$, and depth $3 \mathrm{~cm}$.

\subsection{Electrical Components}

For transforming the mechanical rotation into electrical energy, we bought a gearless Shimano dynamo hub of the type DH-3N20 (Singapore, Republic of Singapore) [24]. We bought this bicycle rim with a dynamo hub from a junkyard for $€ 25$. The nominal power is $3 \mathrm{~W}$ with a voltage of $6 \mathrm{~V}$. At the minimum velocity of $5 \mathrm{~km} / \mathrm{h}$, the dynamo hub reaches the minimum voltage of $3 \mathrm{~V}$. The dynamo hub can be seen in Figure 6b.

For the charge controller, we bought an "M172" product from Kemo Electronics (Geestland, Germany) for $€ 23.99$ that can be seen in Figure 7a [23]. With this charge controller, it is possible to load a smartphone or power bank via USB or flip the switch and supply an electrical consumer with energy. The charge controller was mounted with two screws below the first level of the tower (Figure 7a). The red cable was soldered to the dynamo hub (Figure $7 \mathrm{~b}$ ). The cable for the supply of an electrical consumer was not used in this experiment. The third cable is usually fixed to the frame of the bike to ground the system. In this case, we attached it to the floor. The last cable is the USB charging cable, which can be directly plugged into the power bank or a smartphone.

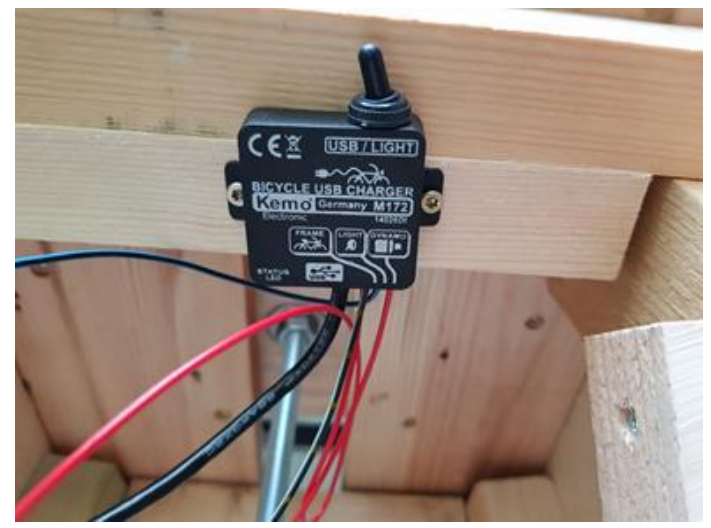

(a)

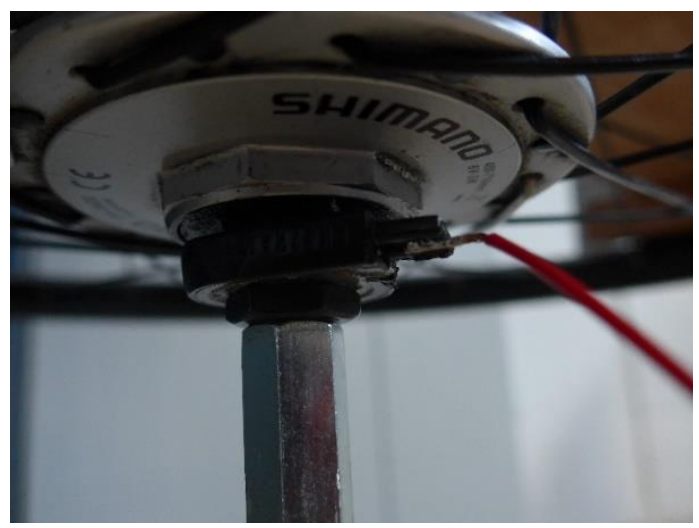

(b)

Figure 7. Mounting the electrical components: (a) charge controller mounted on the first level; (b) connecting the dynamo hub with the charge controller.

As the energy storage system, we used an old WD power bank with a 12,000 mAh capacity (Western Digital, San José, USA). It is possible to charge two devices at the same time, and on a display, the state of charge of the power bank can be seen. There is a flashlight function integrated in the power bank as an additional application. Since it is an old device, it was not possible to get the corresponding data sheet. However, with this setup, any device with a USB connection can be charged and used. The device can be put on the third level platform. To cover it from rain and weather, a small cover or case should be built or some case could be recycled, such as an old plastic box. For this prototype, we did not build such a case.

\section{Results}

With this experiment, we have proved that it is possible to build a Savonius wind turbine from almost only scrap mAterials. Table 1 displays the used mAterials, the place of procurement, and the 
price. Most of the mAterials could be gathered from the junkyard of the university, which is why the total cost of the mAterials was only $€ 65.44$.

\subsection{The Tower}

In this use case, we constructed a wind turbine for a private garden. The tower lifts the rotor above obstacles such as fences; thus, the rotor is in an area with better wind conditions. Furthermore, the rotating parts are out of reach of playing children.

\subsection{The Rotor}

The rotor was $m$ Ade from metal sheets and bicycle rims. To improve the system, a lighter mAterial could be used, and to avoid friction during the rotation, better bearings could improve the system. The Savonius wind turbine does not perform at a high level of efficiency, but the advantages are the reliability and that it can be built and mAintained easily.

\subsection{Electrical Components}

It was not possible to test the Savonius wind turbine in a wind tunnel. Based on information about the Shimano DH-3N20 dynamo hub, the relation of the electric power output and the function of the wind speed is outlined in Table 2.

Table 2. The generated electric power of the dynamo hub DH-3N20 with a $50 \Omega$ resistor at different velocities (speed traveling with the bike (26 in. wheel), not wind speed) [26].

\begin{tabular}{ccccc}
\hline Velocity $\mathbf{( k m} / \mathbf{h})$ & Velocity $\mathbf{( m / s )}$ & Voltage $(\mathbf{V})$ & Current $(\mathbf{m A})$ & Power $(\mathbf{W})$ \\
\hline 0 & 0 & 0 & 0 & 0 \\
5 & 1.49 & 4.2 & 80 & 0.34 \\
10 & 2.78 & 7.88 & 150 & 1.18 \\
15 & 4.17 & 10.5 & 200 & 2.10 \\
20 & 5.56 & 12.86 & 250 & 3.22 \\
25 & 6.94 & 15.12 & 270 & 4.08 \\
30 & 8.33 & 16.66 & 320 & 5.33 \\
35 & 9.72 & 18.37 & 360 & 6.61 \\
\hline
\end{tabular}

More test data of the DH-3N20 hub dynamo can be found online [26]. The power output with a $50 \Omega$ resistor is displayed because it showed the highest power output.

The velocity displayed in Table 2 is not the wind speed but the tip speed of the Savonius wind turbine. The tip speed ratio of Savonius wind turbines is below zero [27]. That is why the actual wind speed, which would mAke the turbine rotate at the velocity displayed in Table 2, would be higher.

With this charge controller and the dynamo hub, it is possible to generate a direct current of $300 \mathrm{~mA}$ with a mAximum voltage of $5 \mathrm{~V}$. The charge controller limits the voltage and current [23].

With the following equation, we calculated the mAximum electrical power that can be generated:

$$
P=U \cdot I=300 \mathrm{~mA} \cdot 5 \mathrm{~V}=1.5 \mathrm{~W} .
$$

The mAximum electrical power that can be generated with this setup is $1.5 \mathrm{~W}$.

We also calculated the time it takes to charge the WD power bank [28]:

$$
\text { charging time to full charge }=\frac{\text { nominal capacity }}{\text { charging current }} \cdot 1.3=\frac{12,000 \mathrm{mAh}}{300 \mathrm{~mA}} \cdot 1.3=52 \mathrm{~h} .
$$

With an assumed efficiency loss of $30 \%$ of the power during the charging process, it takes at least $52 \mathrm{~h}$ to fully charge the power bank-depending on the wind conditions. 
Finally, a rough profitability estimation of the Savonius wind turbine in Bielefeld, Germany emphasizes the necessity of improving the efficiency of the prototype.

The hourly average wind speed at $10 \mathrm{~m}$ height in Bielefeld varies from $20.8 \mathrm{~km} / \mathrm{h}$ in January to $13.8 \mathrm{~km} / \mathrm{h}$ in August [29]. Even though the described prototype is to be placed in a garden and the rotor area is only at $1.4 \mathrm{~m}$ height, the charge controller limits the power yield most of the time. Table 2 shows that at between 10 and $15 \mathrm{~km} / \mathrm{h}$, the mAximum electrical power output of $1.5 \mathrm{~W}$ is already reached.

Assuming the Savonius wind turbine would work $8760 \mathrm{~h}$ a year at nominal power $(1.5 \mathrm{~W})$, it could generate $13.14 \mathrm{kWh} / \mathrm{a}$. The mAterial costs are $€ 65.44$, working hours not included. Assuming further that the prototype could run for 10 years without any mAlfunction, in total, $131.4 \mathrm{kWh}$ could be produced, resulting in a price of $€ 0.5 / \mathrm{kWh}$. In comparison, the average electricity price in 2019 in Germany is $€ 30.85 / \mathrm{kWh}$ [30]. This very optimistic contemplation illustrates that the focus of this study is an educational tool for sensitizing the public to renewable energy in a circular economy and not replacing large-scale wind turbines.

\section{Discussion}

We built an inexpensive wind turbine almost entirely from used mAterials, which could be rebuilt as a DIY project by hobbyists and their children to acquire substantial knowledge about renewable energies and the circular economy. Depending on the size of the wind turbine and the country or region in which it is to be placed, a building permit might be required. This should be evaluated before rebuilding a wind turbine in someone's own garden.

As Section 3.3 demonstrated, the efficiency and energy yield of this wind turbine is not comparable to commercially used wind turbines. However, there is great potential for improvement of this turbine. Instead of a hub dynamo, a dynamo of a scooter could be used to enable higher power generation. The used scrap mAterials were not mAde for use in a renewable energy plant. That is why it is possible that harmful substances could be in or on the wood and metal parts and might be washed out by rain. The best solution would be to design renewable energy harvesting systems circularly from the start.

Since we focused on sensitizing for renewable energies in early childhood education, the most important points are that the system is safe and reliable. If people would build their power plant and someone would get hurt by the turbine, no positive associations with renewable energies would be made.

Another use case could be to provide isolated or poor areas with self-made wind power. As the work of William Kamkwamba shows, electrical and mechanical energy can be provided by harnessing the wind in mAlawi [22].

Rather than providing step-by-step instructions on how to build a self-made wind turbine, this paper should be an inspiration and motivation to become creative and build one's own circular wind turbine. Since the use cases and the available mAterial could vary by place and time, probably every wind turbine is a unique piece of work. Future work could focus on Citizen Science. mAny hobbyists will find new and creative ideas about how to harvest the wind and from which mAterials turbines can be built.

Author Contributions: Conceptualization of the experiment, methodology, resources, and visualization, F.S., A.S., M.S., A.K., and K.H.; validation, E.S.-H.; formal analysis, data curation, writing-original draft preparation, and project administration, F.S.; investigation and writing-review and editing, F.S. and E.S.-H.; supervision, F.S. and E.S.-H.; funding acquisition, F.S. All authors have read and agreed to the published version of the manuscript.

Funding: This article was funded by the Open Access Publication Fund of Bielefeld University of Applied Sciences and the Deutsche Forschungsgemeinschaft (DFG, German Research Foundation)—414001623.

Acknowledgments: We thank Stefan Kollertz from the wood workshop, mAnuel mAi, and the Schülerlabor experiMINT team of Bielefeld University of Applied Sciences for support with tools, advice, and storage space for constructing the wind turbine. We also thank Andrea Ehrmann for constructive criticism of the manuscript.

Conflicts of Interest: The authors declare no conflict of interest. 


\section{References}

1. Arantegui, R.L.; Jäger-Waldau, A. Photovoltaics and wind status in the European Union after the Paris Agreement. Renew. Sustain. Energy Rev. 2018, 81, 2460-2471. [CrossRef]

2. Lütkehus, I.; Salecker, H. Onshore Wind Energy Potential in Germany Current study by the Federal Environment Agency on the nationwide area and output potential. DEWI mAg. 2013, 43, 23-28.

3. Bundesverband Windenergie BWE. Installed Wind Energy Capacity in Germany. Available online: https: //www.wind-energie.de/english/statistics/statistics-germany/ (accessed on 19 August 2019).

4. Pimenta, S.; Pinho, S.T. Recycling carbon fibre reinforced polymers for structural applications: Technology review and mArket outlook. Waste mAnag. 2011, 31, 378-392. [CrossRef] [PubMed]

5. The Japan Carbon Fiber mAnufacturers Association. Available online: www.carbonfiber.gr.jp (accessed on 13 November 2019).

6. Ramirez-Tejeda, K.; Turcotte, D.A.; Pike, S. Unsustainable Wind Turbine Blade Disposal Practices in the United States: A Case for Policy Intervention and Technological Innovation. New Solut. 2017, 26, 581-598. [CrossRef] [PubMed]

7. Neue Westfälische. Available online: https://www.nw.de/lokal/kreis_paderborn/borchen/22081172_Ursachenoch-unklar-Fluegel-von-Windrad-umgeknickt.html (accessed on 14 October 2019).

8. Koh, R. Bio-based Wind Turbine Blades: Renewable Energy Meets Sustainable mAterials for Clean, Green Power. Ph.D. Thesis, University of mAssachusetts, Amherst, mA, USA, 2017.

9. Fraunhofer mAterials. Recycling of Balsa Wood from Rotor Blades for the Production of Insulation mAterials. Available online: https://www.materials.fraunhofer.de/en/business-areas/energy_ and_environment/recycling-of-balsa-wood-from-rotor-blades-for-the-production-of-.html (accessed on 14 October 2019).

10. Razdan, P.; Garrett, P. Life Cycle Assessment of Electricity Production from an Onshore V112-3.45 MW Wind Plant. Vestas 2017. Available online: https://www.vestas.com/ \{\}/media/vestas/about/sustainability/pdfs/ v1123\%2045mw_mk3a_iso_lca_final_31072017.pdf (accessed on 4 December 2019).

11. Fox, T.R. Recycling Wind Turbine Blade Composite mAterial as Aggregate in Concrete. Ph.D. Thesis, Iowa State University, Ames, IA, USA, 2016.

12. Rahimizadeh, A.; Kalman, J.; Henri, R.; Fayazbakhsh, K.; Lessard, L. Recycled Glass Fiber Composites fromWind Turbine Waste for 3D Printing Feedstock: Effects of Fiber Content and Interface on Mechanical Performance. Materials 2019, 12, 3929. [CrossRef] [PubMed]

13. Zotz, F.; Kling, M.; Langner, F.; Hohrath, P.; Born, H.; Feil, A. Entwicklung eines Konzepts und mAßnahmen für einen ressourcensichernden Rückbau von Windenergieanlagen. Umweltbundesamt. Available online: https://www.umweltbundesamt.de/sites/default/files/medien/1410/publikationen/2019_10_ 09_texte_117-2019_uba_weacycle_mit_summary_and_abstract_170719_final_v4_pdfua_0.pdf (accessed on 20 December 2019).

14. RDRWind e.V. Available online: https://www.rdrwind.de/ (accessed on 14 October 2019).

15. Tong, W. Wind Power Generation and Wind Turbine Design; WIT Press: Southampton, UK, 2010; pp. $280-282$.

16. Ellen mAcArthur Foundation. Towards the Circular Economy. Available online: https: //www.ellenmacarthurfoundation.org/assets/downloads/publications/Ellen-MacArthur-FoundationTowards-the-Circular-Economy-vol.1.pdf (accessed on 14 October 2019).

17. Ellen mAcArthur Foundation. Completing the Picture: How the Circular Economy Tackles Climate Change (2019). Available online: www.ellenmacarthurfoundation.org/publications (accessed on 15 October 2019).

18. Al-Bahadly, I. Building a wind turbine for rural home. Energy Sustain. Dev. 2009, 13, 159-165. [CrossRef]

19. Santhakumar, S.; Palanivel, I.; Venkatasubramanian, K. Building a low cost wind turbine in highways for rural house electricity demand. Environ. Prog. Sustain. Energy 2019, 38, 278-285. [CrossRef]

20. Devecitech. Available online: https://devecitech.com/ (accessed on 24 October 2019).

21. Rodrigues, R.; Piper, J.; Bhattacharya, S.; Wilson, S.; Birzer, C. Development of Guidelines for the Construction of Wind Turbines Using Scrap mAterial. Procedia Eng. 2016, 159, 292-299. [CrossRef]

22. Kamkwamba, W.; Mealer, B. The Boy Who Harnessed the Wind: Creating Currents of Electricity and Hope; HarperCollins: New York, NY, USA, 2014.

23. Kemo. Technical Details of the Charge Controller. Available online: https://www.kemo-electronic.de/ datasheets/m172_14026di.pdf (accessed on 20 December 2019). 
24. Shimano. Technical Details of the Hub Dynamo. Available online: https://www.paul-lange.de/tradepro/ shop/artikel/docs/einbauanleitungen/SHIMANO/SI-2YK0A-001-GER.pdf (accessed on 20 December 2019).

25. Sebahattin, T.; Okan, O.T.; mAlkoçoğlu, A.; Ilhan, D. The Use of Some Vegetable Oils as Wood Finishing Substances in Furniture Industry. In Proceedings of the Conference: International Caucasian Forestry Symposium, Seyitler, Turkey, 24-26 October 2013.

26. Shimano DH-3N20. Technical Details of the Hub Dynamo. Available online: http://nightrider.xf.cz/nexus1_ en.htm (accessed on 5 December 2019).

27. Schmelmer, R.; Denk, P. Vertikale Kleinwindanlagen in Bayer Eine Wirtschaftlichkeitsanalyse; Springer: Wiesbaden, Germany, 2014; 13.

28. Retzbach, L. Akkus Und Ladegeräte; GeraMond Verlag: Munich, Germany, 2008.

29. Weather Spark. Durchschnittswetter in Bielefeld. Available online: https://de.weatherspark.com/y/61530/ Durchschnittswetter-in-Bielefeld-Deutschland-das-ganze-Jahr-\%C3\%BCber (accessed on 5 December 2019).

30. Bundesnetzagentur. Wie Setzt Sich Der Strompreis Zusammen? Available online: https://www. bundesnetzagentur.de/SharedDocs/FAQs/DE/Sachgebiete/Energie/Verbraucher/PreiseUndRechnungen/ WieSetztSichDerStrompreisZusammen.html (accessed on 5 December 2019).

(C) 2019 by the authors. Licensee MDPI, Basel, Switzerland. This article is an open access article distributed under the terms and conditions of the Creative Commons Attribution (CC BY) license (http://creativecommons.org/licenses/by/4.0/). 